\title{
Subconjunctival Route of Administration
}

National Cancer Institute

\section{Source}

National Cancer Institute. Subconjunctival Route of Administration. NCI Thesaurus. Code C38298.

The introduction of a substance beneath the conjunctiva. 